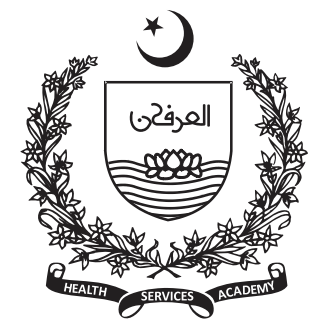

1,2 Final Year MBBS student, FMH College of Medicine and Dentistry, Lahore, Pakistan

${ }^{3}$ Assistant Professor, Community Medicine, FMH College of Medicine and Dentistry, Lahore, Pakistan

4, 5, 6, 7 Final Year MBBS student, FMH College of Medicine and Dentistry, Lahore, Pakistan

Corresponding Author: Naureen Omar Email:

naureen_omar@yahoo.com

\section{Antibiotic Resistance: KAP Study on Medical and Non-Medical Students of Lahore, Pakistan}

Muhammad Talha Iqbal', Maryam Habib Ahmed 2, Naureen Omar'3, Muhammad Raza Ahmed4, Muhammad Fahad5, Muhammad Ali6, Maryam Kaukab ${ }^{7}$

\section{Abstract}

Background: Antibiotics are believed to be safe drugs implying unawareness of people regarding implications of their unchecked overuse, health care professionals being no exception attributed to their attitude and differential practices. Objective was to assess knowledge, attitude and practices regarding antibiotic resistance among medical and non-medical students.

Methods: Descriptive study was conducted in Lahore from March to August 2018. A total of 384 first and second year medical and bachelor students of Fatima Memorial medical college and Nur university were enrolled. Validated questionnaire adopted from WHO survey was used to interview students. Data was analyzed using SPSS version 23. Individual and institutional ethical considerations were fulfilled.

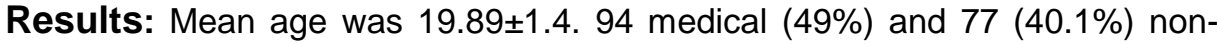
medical students claimed to have taken antibiotics in the previous month, $63.6 \%$ using a prescription, $76 \%$ buying from medical store. Majority $91.7 \%$ (176) medical students were aware of the term "Antibiotic Resistance" compared to $64.1 \%$ (123) non-medical. Antibiotics becomes less effective once resistance develops leading to difficulty in treatment of infections; medical 145(76\%) and nonmedical 137 (71.4\%). Commonest treated diseases sore throat $102(53.1 \%)$ medical and fever $89(46.4 \%)$ non-medical students. Antibiotic resistance is a global issue; $77.6 \%$ (149) medical and 75\% (144) non-medical students.

Conclusion: Majority of students were aware of antibiotics and resistance developing against them with a minimal difference between medical and nonmedical.

Keywords: Antibiotic; Resistance; medical students; Pakistan 


\section{Introduction}

A ntibiotics are medicines used to prevent and treat bacterial infections. Antibiotic resistance occurs when bacteria change in response to the use of these medicines.(1) They are the most frequently prescribed drugs and are often misused, $(2,3)$ thus contributing to the spread of resistant strains of bacteria (4). Their indiscriminate prescribing has increased resistance gene of the commensal flora in hospitals, communities and environment (5). Factors such as patient's demands, doctor's personal experiences, lack of culture and sensitivity results leads to uncertain diagnosis. Sales of antibiotics without prescription has contributed towards antibiotic resistance (6).

In 2011, WHO set the theme of World Health Day as 'Combat Antimicrobial Resistance: No Action Today, No Cure Tomorrow (7). This highlighted the fact that antibiotic abuse is a serious global problem. Between $20 \%$ and $50 \%$ of antibiotic use is either unnecessary or inappropriate (8), and decreasing it is necessary and the first step to curb antibiotic resistance. Antibiotic resistance was perceived as national problem by $95 \%$ of junior doctors, but only $63 \%$ related the problem as important in their own daily practice. Only $31 \%$ and $21 \%$ of doctors knew the correct prevalence of antibiotic misuse of methicillin resistance Staphylococcal Aureus in hospitals $(9,10)$.

Antibiotic use and resistance are not considered to be a major issue by majority of people while considering their choice of drugs even for mild diseases like cold and flu. Antibiotics are believed to be safe drugs implying that people are unaware of the implications resulting due their unchecked overuse (11). Health care professionals also exhibit the same attitudes and practice although it is expected that they should have more knowledge regarding this uprising health challenge which may be attributed to lack of awareness and differential practices $(12,13)$

Despite the wealth of international literature, there is a lack of data about knowledge and counselling practices of healthcare profession students regarding antibiotic resistance in Pakistan. To date, there has been little investigation of students' attitudes towards antibiotic prescribing, and even less of their knowledge and perceptions of antibiotic resistance. A few small mostly single-center studies have found gaps in prescribing knowledge and a desire for further education. $(14,15,16)$ This scarcity of data identifies the need of conducting effective knowledge translation activities and developing guidance related to antibiotic resistance among healthcare profession students in Pakistan. Therefore, before commencing on any interventions to patients or the public, it is necessary to ascertain the understanding of future healthcare practitioners; this study is an attempt in this regard. The objective was to assess the knowledge, attitude and practices of medical and non -medical students regarding antibiotic resistance.

\section{Methodology}

A cross sectional study was conducted in FMH College of Medicine \& Dentistry and Nur International University, Lahore, Pakistan. The study was conducted from March to August 2018. Using a prevalence of $52 \% 18$ at $95 \%$ confidence interval and alpha $5 \%$ using the formula $=\frac{\left(z_{1-\alpha / 2}\right)^{2} P(1-P)}{d^{2}}$, the calculated sample size amounted to 384 .

Non probability convenient sampling was employed comprising of equal number of males and females from first and second year MBBS (192), FMH College of Medicine \& Dentistry and bachelor students (192) from NUR International University.

Data was collected with the help of a validated questionnaire adopted from: WHO research: "Antibiotic Resistance: Multi-Country Public Awareness Survey"17. Students were interviewed by the principal investigators. Data was analyzed using SPSS version 23. Means, standard deviations, frequencies, percentages and proportions were calculated. Permission from the selected institutions was taken. IRB approval and consents of participants was ensured before and during data collection.

\section{Results}

Study was conducted on a sample of 384 students, 192 medical students from FMH College of Medicine and Dentistry and 192 non-medical students from NUR International University. Mean age was $19.89 \pm 1.4,50 \%$ males and $50 \%$ females. When asked as to when they last took antibiotics, 94(49\%) medical and $77(40.1 \%)$ non-medical students claimed to have taken the antibiotics in the last one month. In the total sample, 128(66.7\%) medical and 115(59.9\%) nonmedical students had taken the antibiotics by prescription from a doctor or nurse. Majority, 
$146(76 \%)$ medical, 148(77.1\%) non-medical students bought antibiotics from a medical store or pharmacy. Most of them 137(71.4\%) medical, 123(64.1\%) nonmedical students disagreed to use antibiotics given to a friend or family member to treat the same illness, while 94(49\%) medical and 85(44.3\%) non-medical disagreed to usage of antibiotics previously prescribed for an illness well treated. Mostly 94(49\%) medical, $85(44.3 \%)$ non-medical students disagreed on buying the same antibiotics or requesting for the same prescription if treatment was successful in previous illness (Table-1).

Table 1: Knowledge Regarding Different Terms of Antibiotic Resistance

\begin{tabular}{|c|c|c|c|c|}
\hline \multirow{2}{*}{$\begin{array}{l}\text { Questions } \\
\text { Where did you hear about the term: 'Antibiotic Resistance'? }\end{array}$} & \multicolumn{2}{|c|}{ Medical Students } & \multicolumn{2}{|c|}{ Non-Medical Students } \\
\hline & $\begin{array}{c}n \\
(192)\end{array}$ & $\%$ & $\begin{array}{c}\text { n } \\
(192)\end{array}$ & $\%$ \\
\hline Doctor or Nurse & 56 & 29.2 & 50 & 26 \\
\hline Pharmacist & 15 & 7.8 & 20 & 10.4 \\
\hline Family Member or Friend & 23 & 12 & 26 & 13.5 \\
\hline Media & 17 & 8.9 & 14 & 7.3 \\
\hline Specific Campaign & 6 & 3.1 & 3 & 1.6 \\
\hline Other & 75 & 39.1 & 79 & 41.2 \\
\hline \multicolumn{5}{|l|}{ Where did you hear about the term Antibiotic resistant bacteria? } \\
\hline Doctor or Nurse & 33 & 17.2 & 40 & 20.8 \\
\hline Pharmacist & 16 & 8.3 & 13 & 6.8 \\
\hline Family Member or Friend & 20 & 10.4 & 11 & 5.7 \\
\hline Media & 22 & 11.5 & 16 & 8.3 \\
\hline Specific Campaign & 7 & 3.6 & 3 & 1.6 \\
\hline Other & 94 & 49 & 109 & 56.8 \\
\hline \multicolumn{5}{|l|}{ Where did you hear about the term: 'Superbugs'? } \\
\hline Doctor or Nurse & 15 & 7.8 & 14 & 7.3 \\
\hline Pharmacist & 9 & 4.7 & 14 & 7.3 \\
\hline Family Member or Friend & 4 & 2.1 & 5 & 2.6 \\
\hline Media & 17 & 8.9 & 15 & 7.8 \\
\hline Specific Campaign & 7 & 3.6 & 4 & 2.1 \\
\hline Other & 140 & 72.9 & 140 & 72.9 \\
\hline
\end{tabular}

Majority of the medical students $102(53.1 \%)$ responded in favor of sore throat while $89(46.4 \%)$ non-medical students responded in favor of fever as far as role of antibiotics in treatment of different diseases (Figure 1) Medical students $176(91.7 \%)$ compared to $123(64.1 \%)$ non-medical students were aware of the term "Antibiotic Resistance", mainly heard through different sources. (Table 1). Majority medical $145(76 \%)$ and nonmedical 137 $(71.4 \%)$ students were of the opinion that antibiotics became less effective once resistance develops. Medical 
students $145(76 \%)$ and $96(50 \%)$ non- medical students agreed that antibiotic resistance leads to difficulty in treatment of infections. (Figure 2)

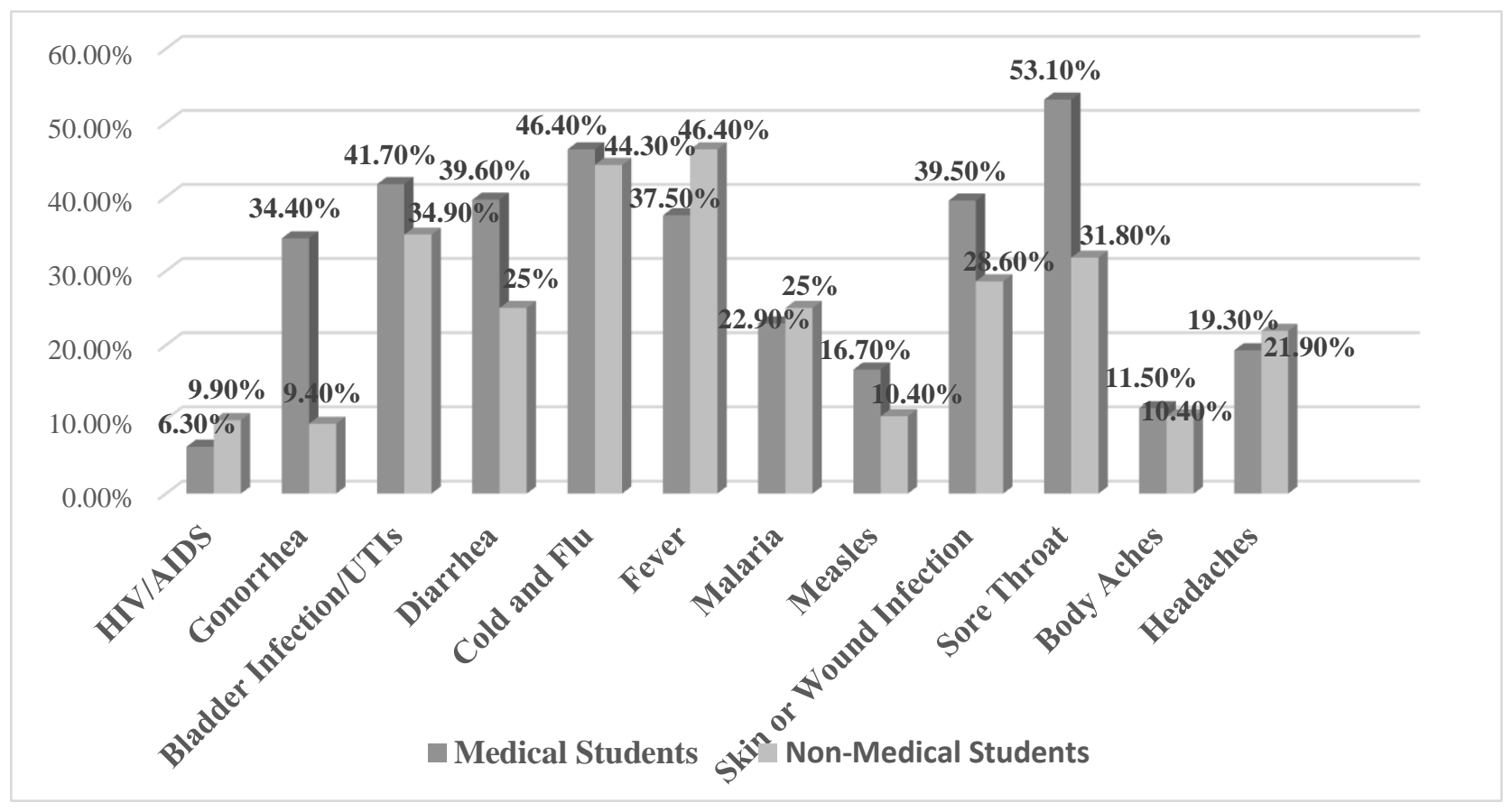

Figure 1: Role of Antibiotics in Treatment of Different Diseases

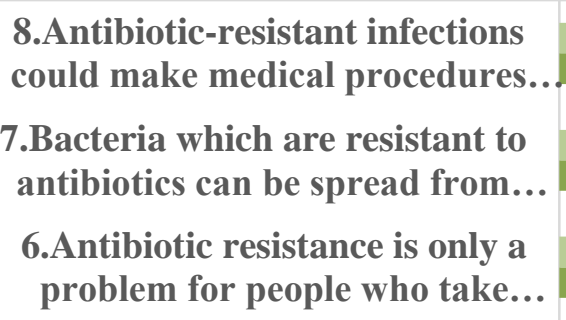

5.Antibiotic resistance is an issue in other countries but not here

4.Antibiotic resistance is an issue that could affect me or my family

3.If bacteria are resistant to antibiotics, it can be very difficult. .

2.Many infections are becoming increasingly resistant to treatment.

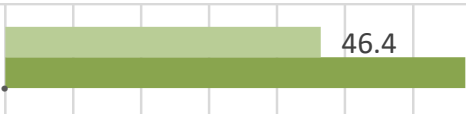

1.Antibiotic resistance occurs when your body becomes resistant to...

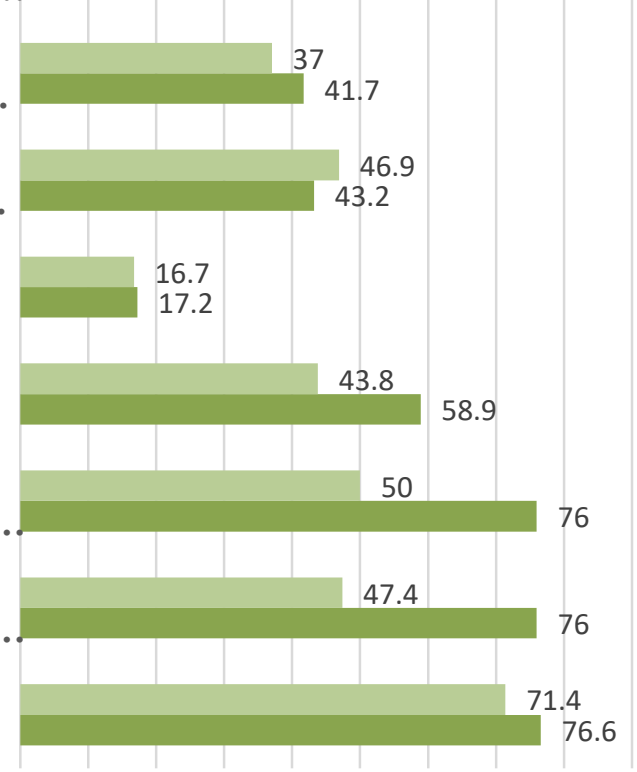

Medical Students Percentage (\%)

$\begin{array}{llllllllll}0 & 10 & 20 & 30 & 40 & 50 & 60 & 70 & 80 & 90\end{array}$

Non-Medical Students Percentage (\%)

Figure 2: Knowledge regarding Antibiotic Resistance of Medical and Non-Medical Students 
Medical 149 (77.6\%) and non-medical 137 (71.4\%) students were of the opinion that antibiotics should only be used when prescribed by healthcare professionals. They strongly agreed that parents need to vaccinate their children according to schedules; 139 (72.4\%) medical and 124 (64.6\%) non-medical students. Regular handwashing should be practiced;138 (71.9\%) medical and 141 (73.4\%) non-medical students. Doctors should prescribe antibiotics when essentially required; 131(68.2\%) medical and $116(60.4 \%)$ non-medical students. (Table 2).

Table 2: Knowledge and Practices: Antibiotic Usage and Antibiotic Resistance in Medical and Non-Medical Students

\begin{tabular}{|c|c|c|c|c|c|c|c|c|c|c|}
\hline \multirow[t]{3}{*}{ Questions } & \multicolumn{2}{|c|}{ Agree Strongly } & \multicolumn{2}{|c|}{ Agree Slightly } & \multicolumn{2}{|c|}{$\begin{array}{l}\text { Neither agree } \\
\text { nor disagree }\end{array}$} & \multicolumn{2}{|c|}{$\begin{array}{l}\text { Disagree } \\
\text { Slightly }\end{array}$} & \multicolumn{2}{|c|}{$\begin{array}{l}\text { Disagree } \\
\text { Strongly }\end{array}$} \\
\hline & Med & NonMed & Med & NonMed & Med & NonMed & Med & $\begin{array}{l}\text { Non } \\
\text { Med }\end{array}$ & Med & $\begin{array}{l}\text { Non } \\
\text { Med }\end{array}$ \\
\hline & $\%$ & $\%$ & $\%$ & $\%$ & $\%$ & $\%$ & $\%$ & $\%$ & $\%$ & $\%$ \\
\hline $\begin{array}{l}\text { Antibiotics should be used only } \\
\text { when they are prescribed by a } \\
\text { doctor or nurse }\end{array}$ & 77.6 & 71.4 & 13 & 17.2 & 3.1 & 8.9 & 3.6 & 1 & 2.6 & 1.6 \\
\hline $\begin{array}{l}\text { Antibiotics should be kept and } \\
\text { used later for illnesses }\end{array}$ & 37.5 & 37.5 & 31.8 & 19.3 & 16.7 & 23.4 & 7.8 & 7.3 & 6.3 & 12.5 \\
\hline $\begin{array}{l}\text { Vaccinations of children should } \\
\text { be complete }\end{array}$ & 72.4 & 64.6 & 15.6 & 19.3 & 8.3 & 9.9 & 2.6 & 4.2 & 1 & 2.1 \\
\hline $\begin{array}{l}\text { Regular handwashing is to be } \\
\text { practiced. }\end{array}$ & 71.9 & 73.4 & 16.1 & 18.8 & 6.8 & 3.1 & 3.1 & 1 & 2.1 & 3.6 \\
\hline $\begin{array}{l}\text { Doctors should only prescribe } \\
\text { antibiotics when they are needed }\end{array}$ & 68.2 & 60.4 & 17.7 & 24 & 7.3 & 12 & 4.2 & 3.1 & 2.6 & 0.5 \\
\hline $\begin{array}{l}\text { Antibiotic resistance is one of the } \\
\text { biggest problems the world faces }\end{array}$ & 39.6 & 41.7 & 38 & 33.3 & 17.7 & 21.4 & 2.1 & 3.1 & 2.5 & 0.5 \\
\hline $\begin{array}{l}\text { Medical experts will solve the } \\
\text { problem of antibiotic resistance } \\
\text { before it becomes too serious }\end{array}$ & 26.6 & 39.6 & 32.3 & 39.6 & 28.1 & 18.2 & 10.9 & 2.6 & 2.1 & 0 \\
\hline $\begin{array}{l}\text { Everyone needs to take } \\
\text { responsibility for using } \\
\text { antibiotics }\end{array}$ & 50.5 & 56.8 & 32.8 & 22.9 & 13.0 & 14.1 & 2.6 & 3.1 & 1 & 3.1 \\
\hline $\begin{array}{l}\text { There are not much people like } \\
\text { me can do to stop antibiotic } \\
\text { resistance }\end{array}$ & 25 & 26.6 & 30.7 & 44.8 & 25 & 16.1 & 12.5 & 7.3 & 6.8 & 5.2 \\
\hline $\begin{array}{l}\text { Impact that antibiotic resistance } \\
\text { on health worries me }\end{array}$ & 38.5 & 30.7 & 30.7 & 35.4 & 21.4 & 24.5 & 4.7 & 6.3 & 4.7 & 3.1 \\
\hline $\begin{array}{l}\text { I am not at risk of getting an } \\
\text { antibiotic- resistant infection if I } \\
\text { take my antibiotics correctly }\end{array}$ & 40.6 & 46.9 & 29.7 & 33.9 & 19.3 & 12.5 & 5.7 & 4.7 & 4.7 & 2.1 \\
\hline
\end{tabular}

\section{Discussion}

Antibiotic resistance is a global issue and it is of utmost importance that medical students understand this uprising issue (18). The current study highlights the areas of difference in knowledge, attitude and perception within medical and nonmedical students. $49 \%$ medical and $40.1 \%$ non-medical students had used antibiotics within the last month, more than half of the medical students enrolled obtained antibiotics with a prescription, quite low in contrast to an Italian study indicating that almost $84 \%$ medical students used a prescription (19). A study conducted in India also supports the fact that majority students had taken antibiotics in the last year but most of them were not using prescriptions (20). The reason 
could be lack of knowledge of students in these countries regarding antibiotic resistance and the practice of self- medication due to availability of drugs over the counter. Most of the medical students were completing the course of treatment with antibiotics as compared to the non-medical students supported by a Malaysian study.(18) These results are in contrast to studies reporting only $15.2 \%$ of medical students stopped the use of antibiotics once they felt better (19) In the current study it was evident that majority were aware of terms like antibiotic resistance, resistant bacteria and superbugs and the main source of information being health professionals, family, friends and media. Very few had gained information from targeted campaigns. In contrast to an Indian study depicting academic courses to be the major source followed by health professionals, media and friends (20). Thus highlighting the need of inclusion of this important topic within the academic curricula.

As far as practices were concerned, re-usage of antibiotics used to treat illness previously in a family member or friend was avoided by a majority of both medical and non-medical students which is concurrent with the findings of a Jordanian study in which majority of the students had the same opinion (16). In contrast to a recent study conducted in India where students were reusing leftover antibiotics without consulting doctors (20).

It was observed that a high percentage of both medical and non-medical students knew that viral infections cannot be treated with antibiotics, an important aspect contributing to antibiotic resistance, supported by a Nepalese study reporting that majority medical students knew that these drugs were used for bacterial rather than viral infections. (21) These results are in contrast to a study depicting belief of medical students being that antibiotics could be used to treat viral infections (22). Another Pakistani study observed that 59\% non-medical students believed that antibiotics were useful against cold and flu while $60 \%$ had inaccurate knowledge of which conditions require the use of antibiotics (23). However, in our study the difference was apparent for bacterial infections, such as gonorrhea, for which $34.4 \%$ medical, and only $9.4 \%$ non-medical students knew that antibiotics were the drug of choice. Thus highlighting the gaps in knowledge of medical students and need for further enhancement of knowledge involving different strata of health professionals.
Interestingly, we found that more than half of the medical students agreed that success of treating infections with antibiotics was reducing due to resistance as compared to less than half of their counterpart. Most of the medical students agreed that antibiotic resistant infections pose a threat to surgical operations, whereas most of the non-medical students disagreed. This evidence is provided by a study indicating that antibiotic resistant strains were a major cause in recurring urinary tract infections in patients who had received kidney transplants (24). Neighboring countries like India and Nepal are facing similar issues as Pakistan because of unregulated sales of medicines over the counter. This provides evidence in support of our study that there is lack of awareness and a dire need to create awareness in order to curb the emergence of antibiotic resistance $(20,21)$. Another study conducted in Pakistan reported that $87.8 \%$ of pharmacists surveyed had rarely or never taken part in any campaign related to antibiotic resistance (25).

We found that medical students had more knowledge than non-medical students regarding the various aspects of antibiotic resistance. There is a need for more programs and campaigns to be implemented in an effort to control the ever-increasing risk of antibiotic resistance (26). We believe that doctors, nurses, pharmacists and healthcare professionals should be involved to help manage antibiotic resistance through increased awareness of medical students and public at a large scale which is the need of the hour as supported by literature (26). One of the big contributors is the over the counter availability of antibiotics which we recommend, if revoked can greatly help limit antibiotic resistance. However, it is a difficult task and it is more practical to employ easier methods such as increased public awareness.

\section{Conclusion}

The study concludes that majority of students were aware of antibiotics and resistance developing against them an a minimal difference was observed between medical and non-medical students. Majority of both study groups were aware of different terms related to antibiotics, superbugs and resistance. The observed difference may be attributed to lack of knowledge regarding antibiotic resistance of nonmedical students and prevailing socio-cultural behavior of common man especially over the counter sales of antibiotics and self-medication. There is dire 
need to develop national guidelines regarding usage of antibiotics and incorporate them within the medical curricula. In addition, academic courses and campaigns need to be conducted within academic institutions.

\section{Acknowledgments}

The authors would like to acknowledge the contributions of Muhammad Asharib Arshad, Shaban Arshad, Muhammad Uzair Afzaal, Myera Siddique, Noor Nadeem, Shahida Ashraf and Shaista Mustafa

\section{References}

1. 1. World Health Organization. Antibiotic Resisitance. 2018.

https://www.who.int/news-room/factsheets/detail/antibiotic-resistance

2. Lin J, Nishino K, Roberts MC, Tolmasky M, Aminov RI, Zhang L. Mechanisms of antibiotic resistance. Front Microbio. 2015;5:6:34.

3. World Health Organization. Antimicrobial Resistance. Global Report on Surveillance. Geneva: WHO. 2014. https://apps.who.int/iris/bitstream/handle/10665/11 2642/9789241564748

4. Centers for Disease Control and Prevention. Antibiotics Aren't Always the Answer.CDC.2013

https://www.cdc.gov/features/antibioticuse/infograp hic2.html

Alvan G, Edlund C, Heddini A. The global need for effective antibiotics-a summary of plenary presentations. Drug Resist Updates. 2011;14(2):70-6.

5. Ventola CL. The antibiotic resistance crisis: part 1: causes and threats. P \& T. 2015;40(4):277.

6. World Health Day. Combat drug resistance: no action today means no cure tomorrow.WHO. 2011

https://www.who.int/mediacentre/news/statements/ 2011/whd_20110407/en/

7. Fridkin S, Baggs J, Fagan R, Magill S, Pollack LA, Malpiedi $\mathrm{P}$, et al. Vital signs: improving antibiotic use among hospitalized patients. MMWR. 2014;63(9):194200.

8. Minen MT, Duquaine D, Marx MA, Weiss D. A survey of knowledge, attitudes, and beliefs of medical students concerning antimicrobial use and resistance. MDR. 2010;16(4):285-9

9. Pulcini C, Williams F, Molinari N, Davey P, Nathwani D. Junior doctors' knowledge and perceptions of antibiotic resistance and prescribing: a survey in France and Scotland. CMI. 2011;17(1):80-7.

10. Jamhour A, El-Kheir A, Salameh P, Hanna PA, Mansour $\mathrm{H}$. Antibiotic knowledge and self-medication practices in a developing country: A cross-sectional study. AJIC. 2017;45(4):384-8.
11. Kasulkar AA, Gupta M. Self medication practices among medical students of a private institute. IJPS. 2015;77(2):178.

12. Ali H, Omar N, Ahmad A, Yasmeen S, Mehmood R, Arshad A. Assessment Of Self-Medication Among Medical And Non-Medical Students. Biomedica. 2015 ;31(4):311.

13. Abbo LM, Cosgrove SE, Pottinger PS, Pereyra M, Sinkowitz-Cochran R, Srinivasan A, et al. Medical students' perceptions and knowledge about antimicrobial stewardship: how are we educating our future prescribers? Clin Infect Dis.2013;57(5):631-8.

14. Khan AKA, Banu G, K KR. Antibiotic Resistance and Usage-A Survey on the Knowledge, Attitude, Perceptions and Practices among the Medical Students of a Southern Indian Teaching Hospital. JCDR. 2013;7(8):1613-6.

15. Ghadeer ARYS. A cross-sectional study on knowledge, attitude and behavior related to $\backslash$ antibiotic use and resistance among medical and non-medical university students in Jordan. AJPP. 2012;6(10).

16. WHO research: "Antibiotic Resistance: Multi-Country Public Awareness Survey" http://www.who.int/antimicrobialresistance/publications/baselinesurveynov2015/en/

17. Kanneppady SS, Oo AM, Lwin OM, Al-Abed AA, Kanneppady SK. Knowledge, attitude, and awareness of antibiotic resistance among medical students. AMHS. 2019 Jan 1;7(1):57.

18. Scaioli G, Gualano MR, Gili R, Masucci S, Bert F, Siliquini R. Antibiotic use: a cross-sectional survey assessing the knowledge, attitudes and practices amongst students of a school of medicine in Italy. PloS one. 2015;10(4):e0122476. 2010;65(6):1292-6.

19. Gupta MK, Vohra C, Raghav P. Assessment of knowledge, attitudes, and practices about antibiotic resistance among medical students in India. JFMPC. 2019 Sep;8(9):2864.

20. Shah P, Shrestha R, Mao Z, Chen Y, Chen Y, Koju P, Liu $X, \mathrm{Li}$ H. Knowledge, Attitude, and Practice Associated with Antibiotic Use among University Students: A Survey in Nepal. IJERPH. 2019 Jan;16(20):3996.

21. Harakeh S, Almatrafi $M$, Ungapen $H$, Hammad $R$, Olayan F, Hakim R, et al. Perceptions of medical students towards antibiotic prescribing for upper respiratory tract infections in Saudi Arabia. BMJ. 2015;2(1):e000078.

22. Arshad MS, Ijaz MF, Hussain A. Evaluation of antibiotic use behavior in cold and flu amongst the students of Bahauddin Zakariya University Multan Pakistan. Pak J Pharm. 2010;23(2):15-22.

23. Bodro M, Sanclemente G, Lipperheide I, Allali M, Marco $\mathrm{F}$, Bosch $\mathrm{J}$, et al. Impact of antibiotic resistance on the development of recurrent and relapsing symptomatic 
urinary tract infection in kidney recipients. Am J Transplant. 2015;15(4):1021-7.

24. Sarwar MR, Saqib A, Iftikhar S, Sadiq T. Knowledge of community pharmacists about antibiotics, and their perceptions and practices regarding antimicrobial stewardship: a cross-sectional study in Punjab, Pakistan. Infect Drug Resist. 2018;11:133-45.
25. Jairoun A, Hassan N, Ali A, Jairoun O, Shahwan M, Hassali M. University students' knowledge, attitudes, and practice regarding antibiotic use and associated factors: a cross-sectional study in the United Arab Emirates. Int J Gen Med. 2019;12:235. 